\title{
Commodity Prices on the Front Line: Boom and Bust?
}

Against the background of high inflation expectations, the seemingly unstoppable rise of commodity prices comes at a critical moment when the European and US economies are struggling to regain the ground lost as a result of the recent financial crisis. Climbing prices are causing mounting worries and anger on the part of both policymakers and the public, for whom it is unthinkable that after the huge amount of resources dedicated to rescuing the financial system from its own troubles, they are now being squeezed by huge spending cuts and soaring commodity prices. There is currently a significant amount of liquidity (M2) in the economy, due to the uncertain global economic outlook and, more importantly, to the loose monetary policies (quantitative easing) implemented by central banks to contain the spillover effects of the financial crisis. This excess liquidity is putting strong upward pressure on prices and may lead central banks to tighten their monetary policies soon by raising interest rates. However, in the eurozone, the government debt crisis may discourage interventions to cool prices, at least in the short run.

The rise of global commodity prices emerges from this intricate context. Prices made an astonishing run in 2010, reaching pre-crisis peaks. Food crises have become a widespread phenomenon, raising fears that growth in emerging markets may ultimately be hindered. For instance, food prices in India have soared by $18 \%$, while the global price of wheat is $80 \%$ higher than last year. This situation is fomenting outrage in the poorest countries across the world, creating strong political instability (e.g. Tunisia).

Besides economic uncertainty, the increase in commodity prices may have several explanations. There are two conflicting views on the surge in commodity prices, in particular on the role of the "financialisation" of commodities, i.e. investments in commodity indexes and dominant net positions in derivatives markets (primarily futures and options). On the one hand are those who believe that the large increase in commodity prices has a positive correlation with investment in commodity indexes. This position clearly shows its limits when it comes to providing empirical evidence of an immediate link between soaring trading in commodity indexes and spot prices. The strong positive correlation between, for instance, energy and non-energy commodity prices may be explained by many other factors, such as the impact of transportation costs (linked to the oil price) on the price of non-energy commodities or the prevailing exchange rates (the dollar, in particular). However, positive price correlation among commodities has consistently increased, especially in the last decade, even though this value was negative at the beginning of the new century.

On the other hand, many authors (e.g. Krugman) argue that commodities are in a boom-andbust cycle, driven by the rapid growth of emerging countries. The difference between supply and demand (net demand) determines the level of prices by reducing or increasing the stockpile levels, which ultimately affects spot prices. This position seems more plausible, but it does not dig deeply enough into the complexity of the issue.

Other factors that can affect stockpile levels and consequently spot prices include price volatility, futures prices, supply constraints, transportation costs, market settings and exogenous factors (e.g. wars). Historically, price volatility in commodity markets has been high. However, in recent years, the growing uncertainty surrounding the economic outlook, mainly stemming from the financial crisis, has boosted volatility even higher. Most notably, the daily standard deviation of a major commodity index (TRJ-CRB index) exploded from 7.15 in 1994 to 74.22 in 2008 before settling down to a relatively more stable figure in 2009 (22.68). Uncertainty exerts a crucial influence on production levels. Futures prices may be more generally affected by the financialisation process. For instance, by holding a dominant net position in a commodity for 
a particular settlement date (a so-called "settlement squeeze"), futures prices may be driven up, which has a similar, though more limited, effect on spot prices. Supply constraints, such as limited extraction activities due to environment sustainability measures, may also reduce the level of stockpiles and increase spot prices. Higher spot prices may also be the result of the competitive design of a commodity market, e.g. the OPEC cartel's efforts to determine the oil price by manipulating the extraction and distribution of oil. Likewise, exogenous factors are a primary source of price changes. In 2010, weather and other exogenous shocks, such as war tensions in some Middle Eastern countries, have affected the production levels of large exporters. The supply shock has significantly contributed to upward pressure on food prices.

The substantial growth of uncertainty, evidenced by the rise in the prices of commodities such as gold, has increased producers' needs to find protection through the use of sophisticated financial transactions, particularly in derivatives markets. These markets provide formidable means of hedging against price changes in the physical product. However, regulators should shed some light on the risks of price manipulation potentially arising from the accumulation of dominant net positions in these markets. The attempt to squeeze the market by collecting a dominant share of a commodity future for a specific settlement date may have disruptive effects on spot prices, since the dominant owner of a long position for that date may exercise unreasonable upward pressure on futures prices and thereby indirectly on spot market prices as well. To reduce the harmful effects of settlement squeezes, regulators and supervisors typically adopt two tools: position limits and position management. Position limits generally impose a cap on the size of commodity traders' transactions. Some argue, however, that these measures can be easily circumvented by trading more frequently with smaller sizes, which makes supervision more difficult. Position management instead seems to be a more effective tool for tackling this issue, since manipulation in commodity markets does not usually result from the price impact of the availability of investors to transact a security at a specific price but rather from the availability of counterparties to bargain a future position. Since the availability of settlement dates is actually quite limited, it would be more meaningful to collect all trading reports and calculate the total net position of an investor in that specific market. Position management allows the detection of dominant net positions at the end of the trading day. If these positions create unreasonable upward or downward pressures on prices, market operators can require traders, at the beginning of the next trading day, to reduce their positions.

The sharp and global increase in commodity prices has alarmed the world. Fears that rising food and commodity prices can create severe political instability and violent internal and crossborder tensions have prompted global policymakers (e.g. the G20) to issue warnings about the future of the global economy. The reasons for this dramatic rise are multiple, and engaging in a witch-hunt against speculators would benefit neither the market as a whole nor our economies. Solutions need to be more differentiated and oriented towards two factors: price manipulation and sustainability. Reducing the market conditions that can stimulate manipulative behaviour means not only intervening in financial markets to limit price manipulation through dominant net positions but also creating competitive market settings where production becomes gradually less subject to manipulation by vested interests and cartels. Finally, more attention must be given to the elephant in the room - the unsustainability of uncontrolled growth in emerging markets that can ultimately generate strong incentives to increase profits by wasting natural resources if not properly managed. The future challenge will be not so much to capture the complexity of these variables in a sophisticated mathematical model to predict price movements but rather to hold all these variables together to design more efficient and sustainable policies. Ultimately, prices are only the warning signal of a more fundamental problem that looms over global economies. 